\title{
CULTURAL DIFFERENCES IN AGGRESSION: A CASE STUDY IN BANGLADESH
}

\author{
A. K. M. Rezanur Rahman* \\ Department of Psychology, Baneswar College, Rajshahi, Bangladesh
}

\begin{abstract}
The present study was to examine gender and cultural differences in aggressive behaviour in the context of Bangladesh. Sample was selected from two cultural backgrounds such as Bengali culture and Santal culture in different areas of Rajshahi District. A total of 160 respondents were randomly selected from Santal and Bengali culture populations. A $2 \times 2 \times 2$ factorial design representing two levels of cultural group (Bengali / Santal), two levels of residential background (urban / rural) and two levels of sex (male / female) was used in the study. The Measure of Aggressive Behaviour was used for data collection. The data were analyzed using Analysis of Variance. It was found that Bengali respondents expressed more aggression than Santal respondents. Residential background and sex differences were also observed. Thus culture emerged as an important factor in aggression.
\end{abstract}

Key words: Aggression, antisocial behaviour, gender differences, residential background, culture

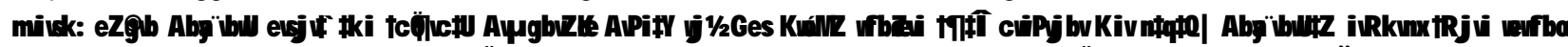

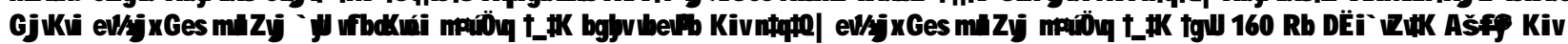

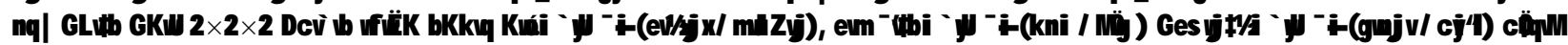

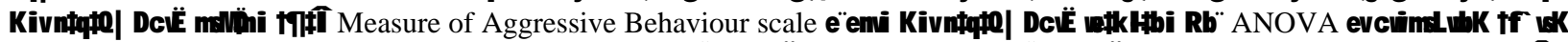

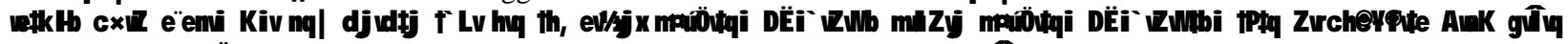

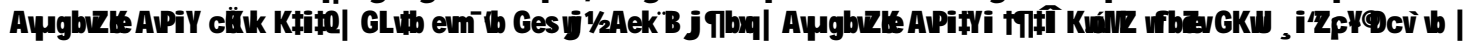

\section{Introduction}

Aggression is a form of social behaviour. It is also distinguished on the parameter of antisocial and prosocial aggression. Unprovoked criminal acts are antisocial aggression. For example, assault and battery, murder and gang beating clearly violate social norms. So these are described as antisocial aggression. But aggressive acts dictated by social norms are called prosocial aggression. For example, acts of law enforcement, appropriate parental discipline or obeying the orders of commanders in wartime are regarded as necessary and may be classified as prosocial aggression.

Some aggressive acts fall somewhere between prosocial and antisocial aggression. We may level them sanctioned aggression. This includes aggressive acts that are not required by social norms, but that are well within their bounds. They do not violate accepted moral standards. For example, a coach may punish a disobedient player for the sake of discipline. A shopkeeper may assault a criminal for the sake of selfdefense. A woman may strike back a rapist. None of these acts is required of the person, but they fall within the bounds of what is permitted by social norms.

Culture is an important factor that plays a role in aggression. Anthropological research has found that some cultures are relatively low on aggression (Keeley

*Correspondence: rrnilu@gmail.com
1996). Empirical cross-cultural research has found differences in the level of aggression between cultures. Andreu et al. (1998) found that American men resorted to physical aggression more readily than Japanese or Spanish men, whereas Japanese men preferred direct verbal conflict more than their American and Spanish counterparts. Bowdle et al. (1996) conducted a survey to explain the variation in aggression within the same culture. They found that the Southerner Americans were more aggressive than Northerner Americans. Nisbett (1993) observed higher homicide rate among young White Southern men than among White Northern men in the United States. Southerners appear to be more likely to subscribe to a "culture of honor" and adopt violence in response to insults.

Socio-cultural factors such as changes in family roles, divorce, child abuse, unemployed parents, and community racial tension are often regarded as contributing factors to personal violence in the schools. In addition, urban society tends to be violent, and some aspects of this violence overflow into the schools (Nuttal and Kalesnik 1987). Poverty may be another important factor in aggression. Poverty decreases the essential resources necessary for social development and increases the stressors that impede effective parenting and problem solving (Nuttal and Kalesnik 1987). 


\section{Materials and Methods}

Subjects: The subjects in this study constituted total 160 respondents of two categories of Bengali and Santal cultural groups from different urban and rural areas of Rajshahi District. Each category was again divided into males and females. Each subgroup was then equally divided into urban and rural. Then they were selected randomly. Thus a stratified random sampling procedure was taken for the selection of the subjects in the study.

Instrument: Following Buss and Perry (1992), Rahman (2003) constructed the Measure of Aggressive Behaviour scale (MAB). The MAB was adopted in Bengali version (Rahman,2003). It contains 25 items were used for data collection. The items were divided into five dimensions such as physical aggression (5 items), verbal aggression (9 items), hostile aggression (5 items), anger aggression (3 items) and indirect aggression (3 items). Hypothetical situations were constructed on each item. Each item was followed by 5 alternatives ranging from totally true to totally false. Totally true was given 5 points, true was given 4 points, neutral was given 3 points, false was given 2 points and totally false was given 1 point. The Highest Possible Score (HPS) was $25 \times 5=125$ and the Lowest Possible Score (LPS) was $25 \times 1=25$. Aggressive Behaviour Score (ABS) was worked out using the following formula.

$$
\mathrm{ABS}=\frac{\mathrm{HPS}-\mathrm{LPS}}{2}+\mathrm{LPS}=\frac{125-25}{2}+25=75
$$

Hence, a score following on 75 or above was regarded as Aggressive Behaviour Score.

The correlation coefficient for split-half reliability was found .37. When Spearman-Brown formula was used, the correlation coefficient was found to increase from .37 to .54. The Measure of Aggressive Behaviour was confirmed by validation at several stages. Items were constructed through open-end questionnaire. This indicated the content validity of MAB. Secondly, the scrutiny of each item was done by the judges. This procedure provided face validity for the Measure of Aggressive Behaviour

Design of the study: The study used a $2 \times 2 \times 2$ factorial design consisting of two levels of cultural group (Bengali / Santal), two levels of residential background (urban / rural) and two levels of sex (male/female) was used in the study. Analysis of Variance (ANOVA) was computed on total score of the MAB. Three independent variables such as (i) gender (ii) residential background and (iii) cultural group were used.

Procedure: The MAB was administered on 160 respondents. Eighty respondents of them were Bengali culture and the remaining eighty respondents were Santal culture. The investigator contacted each respondent individually and proper rapport was established. They were collected from different urban and rural areas of Rajshahi District. In first phase, 20 male respondents with Bengali culture from urban residential background were selected for data collection. In the second phase, 20 male respondents with Santal culture from urban residential background were selected for data collection. Following this procedure, 20 male respondents with Bengali culture from rural residential background and 20 male respondents with Santal culture from rural residential background were selected for data collection. Similar procedure was maintained for female respondents for data collection. As soon as the data collection was completed, coding was done properly for statistical analysis of the data.

\section{Results and Discussion}

The summary of ANOVA has been reported in table-1. The results on total score of the MAB showed that the main effect of gender and cultural group were statistically significant $(\mathrm{F}=9.646, \mathrm{df}=1 / 152, \mathrm{p}<0.01$; and $\mathrm{F}=34.215$, $\mathrm{df}=1 / 152, \mathrm{p}<0.001)$. A two-way interaction between gender and residential background was statistically significant, $(\mathrm{F}=19.172, \mathrm{df}=1 / 152, \mathrm{p}<0.001)$.

Table 1. ANOVA involving gender, residential background and cultural group on total score of the MAB.

\begin{tabular}{|c|c|c|c|c|}
\hline $\begin{array}{l}\text { Sources of } \\
\text { variance }\end{array}$ & SS & df & MS & $\mathrm{F}$ \\
\hline Gender (A) & 500.6 & 1 & 500.6 & $9.646 * *$ \\
\hline $\begin{array}{c}\text { Residential } \\
\text { background } \\
\text { (B) }\end{array}$ & 77.06 & 1 & 77.06 & $1.484 \mathrm{~ns}$ \\
\hline $\begin{array}{l}\text { Cultural group } \\
\text { (C) }\end{array}$ & 1775.61 & 1 & 1775.61 & $34.215^{* * *}$ \\
\hline $\mathrm{A} \times \mathrm{B}$ & 994.965 & 1 & 994.965 & $19.172 * * *$ \\
\hline $\mathrm{A} \times \mathrm{C}$ & 1.765 & 1 & 1.765 & $0.034 \mathrm{~ns}$ \\
\hline $\mathrm{B} \times \mathrm{C}$ & 66.255 & 1 & 66.255 & $1.276 \mathrm{~ns}$ \\
\hline $\mathrm{A} \times \mathrm{B} \times \mathrm{C}$ & 7.695 & 1 & 7.695 & $0.148 \mathrm{~ns}$ \\
\hline $\begin{array}{l}\text { Within cell } \\
\text { (Error) }\end{array}$ & 7888.05 & 152 & 51.895 & \\
\hline Total & 11312 & 159 & & \\
\hline
\end{tabular}

Ns= Not significant; ${ }^{*} \mathrm{P}<0.05$; $^{* *} \mathrm{P}<0.01$; $^{* * *} \mathrm{P}<0.001$. 
Table 2. Mean scores and significant mean differences between gender and cultural group respondents $(\mathrm{N}=80$ for each groups).

\begin{tabular}{|c|c|c|}
\hline Parameters & Respondents & Mean scores \\
\hline \multirow{2}{*}{ Gender } & Male & $73.71^{\mathrm{a}}$ \\
\cline { 2 - 3 } & Female & $77.25^{\mathrm{b}}$ \\
\hline \multirow{2}{*}{ Cultural groups } & Bengali & $78.81^{\mathrm{a}}$ \\
\cline { 2 - 3 } & Santal & $72.15^{\mathrm{b}}$ \\
\hline
\end{tabular}

Note: Common superscripts do not differ significantly. NewmanKeuls formula was used for the computation of mean differences.

The results of ANOVA shows significant main effect for gender $(\mathrm{F}=9.646, \mathrm{df}=1 / 152, \mathrm{P}<0.01)$. An inspection of mean scores (table-2) shows that regardless of residential background and cultural group, the female respondents ( $M=77.25)$ expressed significantly higher aggression as compared to male respondents $(\mathrm{M}=73.71)$. Similarly, ANOVA shows significant main effect for cultural group $(\mathrm{F}=34.215, \mathrm{df}=1 / 152, \mathrm{P}<0.001)$. An inspection of mean scores (Table 2) shows that regardless of gender and residential background, the Bengali respondents ( $M=78.81)$ expressed significantly higher aggression as compared to Santal respondents $(\mathrm{M}=72.15)$.

Table 3. Mean scores and significant mean differences of two-way interaction between gender and residential background ( $\mathrm{N}=40$ for each groups)

\begin{tabular}{|c|c|c|}
\hline Gender & \multicolumn{2}{|c|}{ Residential background } \\
\hline & Urban & Rural \\
\hline Male & $70.52^{\mathrm{a}}$ & $76.90^{\mathrm{b}}$ \\
\hline Female & $79.05^{\mathrm{c}}$ & $75.45^{\mathrm{b}}$ \\
\hline
\end{tabular}

Note: Common superscripts do not differ significantly. NewmanKeuls formula was used for the computation of mean differences.

Interaction between gender and residential background: The results (Table 1) showed that a two-way interaction involving gender and residential background was statistically significant $(\mathrm{F}=19.17, \mathrm{df}=1 / 152, \mathrm{p}<0.001)$. The mean scores reported in (Table 3 ) showed that female respondents with urban residential background ( $M=79.05)$ expressed significantly higher aggression than male respondents with urban residential background $(\mathrm{M}=70.52)$ as well as to their rural counterparts (75.45). Again, male respondents with urban residential background $(\mathrm{M}=76.90)$ expressed significantly higher aggression than their counterparts with urban residential background $(M=70.52)$. However, in case of rural residential background, no significant mean difference noticed between male and female respondents.

This finding about greater aggression in women than men has been supported by some research findings conducted in recent years. Thus, Lanctot et al. (2003) conducted the Gender and Aggression Project (GAP) in Canadian Institutes for Health Research (CIHR) and reported that gender difference in aggression have several forms. It was concluded that females tend to engage more in relational aggression, but males tend to engage more in physical aggression (Crick 1995). These findings partially supported the findings of the present study relating to gender differences in aggression.

One probable explanation of this finding might be related with the domain-specific theory of self-esteem (Rosenberg 1965; Rubin and Hewstone 1998; Baumeister 1998; Kirkpatrick et al. 2002). This theory states that functionally distinct domains of self-esteem would predict aggression differentially. It is, perhaps, important to note that socio-cultural group or status may be regarded as functionally distinct domains of selfesteem. The persons with high socio-cultural group or status perceive superiority. The persons with low sociocultural group or status, on other hand, perceive social exclusion. Thus, social superiority and social exclusion emerged as reliable and positive predictor of hostile aggression (Baumeister and Boden 1998; Bushman and Baumeister 1998).

The findings of the present study may be approached from the view-point of these theoretical perspectives. The Bengali respondents who are high in socio- cultural group or status might perceive superiority as the predictor of self-esteem. The Santal respondents who are low socio-cultural group or status might perceive inferiority and social exclusion. Hence, it might be argued that feelings of superiority would increase aggression and the feelings of social exclusion and inferiority would decrease aggression.

This finding about socio- cultural group or status may be explained in terms of social power. The Bengali respondents possess more social power in terms of dominance and wealth leading to more aggressive behaviour. The Santal respondents possess less social power in terms of dominance, prestige and wealth leading to relatively lower frequency in aggressive behaviour.

In the context of Bangladesh, Bengali respondents have more wealth, more self-esteem, more prestige and they can dominate the people belonging to Santal respondents. It is, perhaps, these reasons that are responsible for differential aggression in people with high and low socio-cultural group or status in the context of Bangladesh. 
In the present study, a two-way interaction involving gender and residential background has shown that male respondents with rural residential background expressed more aggression as compared to male respondents with urban residential background. But, female respondents with urban residential background expressed more aggression as compared to female respondents with rural residential background as well as male respondents with urban residential background. These findings showed that both gender and residential background have moderating effect on aggression. It is clear that a large number of social factors are related with aggression of gender differences.

The results also showed that residential background and cultural group has moderating effect on aggression. It is important to note that urban and rural residential background has several social and economic implications that might be responsible for moderating effect on aggression. The social implication may be explored in cultural groups.

\section{Conclusion}

In conclusion, it may be said that aggression is a serious problem in individual, social, national and international spheres. The present study was conducted to explore aggressive behaviour in cultural factors in the context of Bangladesh. Aggression as biological, social and environmental phenomenon has arrested the attention of social psychologists and as such the present investigation reflects on some important aspects of aggression in relation to gender, cultural group and residential background. The computation of data has provided some important findings on gender, cultural group and residential background responsible for induction of aggression. Findings of the present study replicate the previous findings and justify the results about aggression in gender differences and cultural groups stemming from the data.

\section{References}

Andreu, J. Manuel, Takehiro Fujihara, Takaya Kohyama, and J. Martin Ramirez. 1998. Justification of Interpersonal Aggression in Japanese, American, and Spanish Students. Aggressive Behavior 25: 185-195. 7 Dec. 2006.

Baumeister, R. F. 1998. The self. In: D. T. Gilbert, S. T. Fiske, \& G. Lindzey (Eds.), The Handbook of Social Psychology (Vol. 1, 4th ed., pp. 680-740). New York: McGraw-Hill.
Baumeister, R. F. and Boden, J. M. 1998. Aggression and the self: High self-esteem, low self-control, and ego threat. In: R. Geen and E. Donnerstein (Eds.), Human Aggression: Theories, Research, and Implications for Social Policy (pp. 111-137). San Diego, CA: Academic.

Bowdle, Brian F., Dov Cohen, Richerd E. Nisbett and Norbert Schwarz. 1996. Insult, Aggression, and the Southern Culture of Honor: An Experimental. Journal of Personality and Social Psychology 70: 945-960. 7 Dec. 2006.

Bushman, B. J. and Baumeister, R. F. 1998. Threatened egotism, narcissism, self-esteem, and direct and displaced aggression: Does self-love or self-hate lead to violence? Journal of Personality and Social Psychology, 75, 219229.

Buss, A. H. and Perry, M. P. 1992. The aggression questionnaire. Journal of Personality and Social Psychology, 63, 452-459.

Crick, N. R. 1995. Relational aggression: The role of intent attributions, feelings of distress, and provocation type. Development and Psychopathology, 7, 313-322.

Keeley, L. H. 1996. War Before Civilization: The Myth of the Peaceful Savage. New York: Oxford University Press.

Kirkpatrick, L. A., Waugh, C. E., Valencia, A. and Webster, G. D. 2002. The functional domain specificity of selfesteem and the differential prediction of aggression. Journal of Personality and Social Psychology, 82, 756767.

Lanctot, N. and LeBlanc, M. 2003. The structure and growth of violence Interdisciplinary Conference, Edinburgh, 712 , July.

Nisbett, R. E. 1993. Violence and U.S. regional culture. American Psychologist, 48, 441-449.

Nuttal, E. V. and Kalesnik, J. 1987. Personal violence in the schools: Th erole of the counselor. Journal of Counseling and Development, 65, 372-375.

Rahman, A.K.M. Rezanur. 2003. Psycho-Social Factors in Aggressive Behaviour in Males and Females in Bangladesh. Unpub. M. Phil. Thesis. Dept. of Psychology. University of Rajshahi, Bangladesh.

Rosenberg, M. 1965. Society and the Adolescent Self-image. Princeton, NJ: Princeton University Press.

Rubin, M. and Hewstone, M. 1998. Social identity theory's self-esteem hypothesis: A review and some suggestions for clarification. Personality and Social Psychology Review, 2, 40-62. 